\title{
3D Information System of Historical Site - Proposal and Realisation of a Functional Prototype
}

\author{
J. Hodač
}

The development of methods for $3 D$ data acquisition, together with progress in information technologies raises the question of creating and using 3D models and 3D information systems (IS) of historical sites and buildings. This paper presents the current state of the "Live Theatre" project. The theme of the project is the proposal and realisation of a 3D IS of the baroque theatre at Česky Krumlov castle (UNESCO site).

The project is divided into three main stages - creation of a 3D model, proposal of a conception for a 3D IS, and realisation of a functional prototype. 3D data was acquired by means of photogrammetric and surveying methods. An accurate 3D model (photo-realistic, textured) was built up with MicroStation CAD system. The proposal of a conception of a 3D IS was the main outcome of the author's dissertation. The essential feature of the proposed conception is the creation of subsystems targeted on three spheres-management, research and presentation of the site. The functionality of each subsystem is connected with its related sphere however, each subsystem uses the same database. The present stage of the project involves making a functional prototype (with sample data). During this stage we are working on several basic technological topics. At present we are concerned with $3 D$ data, its formats, format conversions (e.g. DGN $\Rightarrow$ VRML) and its connection to other types of data. After that, we will be seeking a convenient technical solution based on network technologies (Internet) and an appropriate layout for the data (database). The project is being carried out in close co-operation with the administration of the castle and some other partners. This stage of the project will be completed in December 2005.

A functional prototype and the information acquired by testing it will form the basis for the final proposal of a complex IS of a historical site. The final proposal and appropriate technology will be the outcome of the project. The realisation of a complex $3 D I S$ will then follow. The results will be exploitable both for site management and for organisations working in the area of presenting historical sites and creating multimedia shows.

Keywords: cultural heritage, 3D information sciences, system, project, proposal, development, virtual reality, Internet/web.

\section{Introduction}

Progress in information technologies together with the development of geodetic and photogrammetric documentation methods has led to new opportunities for creating and using of $3 \mathrm{D}$ models of historical sites and buildings. This paper presents the current state of the "Live Theatre" project. The main goal of the project is to propose and implement a functional prototype of a 3D information system for a particular historical site. The theoretical foundations of the project were established in [1], which deals with ways from gathering $3 \mathrm{D}$ documentation to creation of a 3D IS.

\subsection{Background of the project}

Information processing has been increasing in importance, and progress in information technologies and computer technologies has been accelerating. Information systems are coming into use in areas, where they were not considered in the past. The cultural heritage is such an area in our country. Apart from the main content of information, localisation and time are becoming very important aspects today. There is a movement from IS working with 2D information (planar data) toward IS working with 3D information (3D models) and time, see e.g. [2]. Another movement is connected with the development of network technologies. Information systems are moving from separated offices to the net and Internet. Work with 3D data is closely connected with development in computer graphics (virtual reality).
The cultural heritage area is now more important also because of its relation to the tourist industry. Historical sites, together with areas of natural beauty are the most popular targets both in the Czech Republic (CZ) and abroad. This is again connected with information. If a historical site is to attract potential visitors, it needs to be well presented. Presentation on the Internet can be very effective. In this context we can hear terms such as virtual tourism, virtual sightseeing and virtual monuments or sites, see e.g. [3]. The importance of 3D data in this area is growing.

The Laboratory of Photogrammetry at the Department of Mapping and Cartography has been cooperating with the administration of Český Krumlov castle and the Baroque Theatre Foundation on a project to create of metrical documentation of the castle's baroque theatre. This co-operation has been running since 1996, see [4]. The theatre is primarily documented by students of geodesy and cartography working on diploma projects. The aim of the first phase of the project is to create new metrical documentation of the theatre in the form of a 3D model. In the second phase, the 3D model will form the core of a 3D information system.

\subsection{Motivation and aim of the project}

It is not a major technical problem today to acquire $3 \mathrm{D}$ data and to create a 3D model of an object, e.g., in the area of cultural heritage. The question I met with was: how to use this $3 D$ model effectively? Currently, customers demand documentation predominantly in 2D form, and they do not want 3D data and models. Models are used for once-off 
purposes, e.g., for presentation (visualization) or research of a site. Other applications for these models are uncertain. This is discouraging, because of the amount of work involved in creating the models.

Utilisation of 3D data in 3D IS is a promising prospect. In connection with IS of historical sites it is necessary to ask: What ideas do the owners or administrators of sites have? Do they need IS, do they need 3D data? If yes, what data and for what purposes? The answers to these questions formed the basis for defining the aims of this project.

The main aim of the project is: to find good ways from gathering $3 D$ documentation to creation of a $3 D$ information system of a historical site.

\section{Phases of the project}

The project is divided into three main stages - creation of a 3D model, proposal of a conception for a 3D information system, and realisation of a functional prototype. This paper focuses on the second stage. A detailed description of this stage follows.

Discussions with administrators of sites and also experience from professional meetings in the last decade, see, e.g., [3], formed the basis for the defining the basic areas for using 3D data. Fig. 1 describes these areas, the most important of which are: presentation of the site, research of the site, and management of the site. In all of these areas we use similar initial data. The methods for processing this data vary according to the user's requirements.

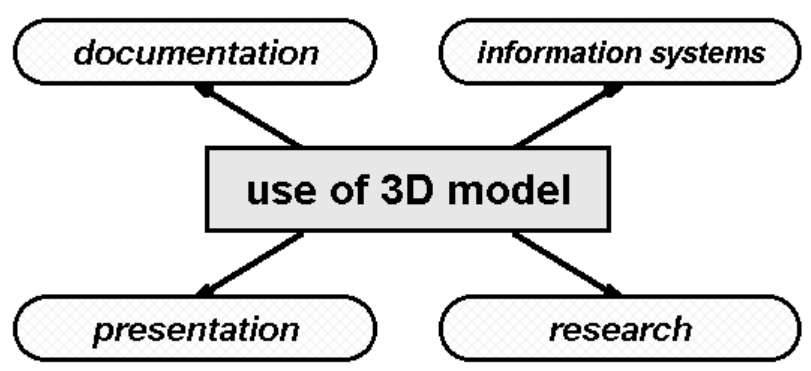

Fig. 1: Fields of utilisation of 3D models

The second stage of the project was divided into three parts - analytical, synthetic and application.

In the analytical part, attention was paid to two target areas: site management and site presentation. An analysis was made of the current state of the data used by site administrators. The types of operation using data were also examined. The last part of this analysis dealt with conditions for utilising information technologies in the analysed area. Another analysis focused on the current state of presentations of historical sites on the Internet in the Czech Republic and abroad. Virtual tourism, virtual sites and the tourist industry were at the focus of this analysis.

The results of these analyses formed the basis for the proposal for the conception of IS of a historical site in the synthetic part of the project. This proposal works with three main application areas - site presentation, site research and site management.

The application part of the project was also very important. A proposal was created for a conception of an infor- mation system for the baroque theatre in the castle at Český Krumlov ("Live Theatre" project). Primary attention was given to designing data schemes for each part of IS.

\subsection{Analysis - site management}

The data for this analysis was acquired with the use of a questionnaire, which included questions on the following topics: affordable plan documentation (geometrical data), affordable inventories, tallies (non-geometric data), technical and organisational background. The inquiry was conducted at 24 selected sites located in South Bohemia. The main condition for the selection of sites was accessibility for the public. Most of the selected sites were large (e.g. castles) and they were owned by the state.

The results of the questionnaire showed that the administrations of the sites tend to be rather small organisations, with not more than 5 employees. Some of them are able to use services provided by the founder (mainly sites owned by the state). The organisations are equipped with computers only on a basic level, and connectivity to the Internet is limited. Utilisation of information technologies is rated positively by the staff. Unfortunately, the real situation in the administrative offices is not so good, and the use of these technologies is not widespread. The respondents considered that the main barrier to wider use is cost.

The quality of the existing documentation is assessed by the respondents as sufficient for current utilisation. A combination of traditional paper documentation with digital documentation would be optimal according to most of the respondents.

\subsection{Analysis - site presentation}

The selected sites (in CZ) were the same as in the analysis above. The topics for investigation were: existence and content of presentation, language of presentation, use of multimedia, services, the place where the presentation is available, and graphical quality.

Approximately 15 foreign presentations and projects were analysed. The main focus was on the UK, because of the richness of its cultural heritage. Other sites and projects dealing with the virtual heritage, and virtual tourism were included in the selection.

The results of the analysis of sites located in CZ showed that we cannot speak of virtual tourism today. Most presentations do not use interactive elements and geometrical data (plan, maps, and 3D models). Most are static, not living presentations. Complex presentations consisting of voluminous sets of information are still only sporadic. Links to other types of information systems (town, region, national, tourist industry etc.) are lacking.

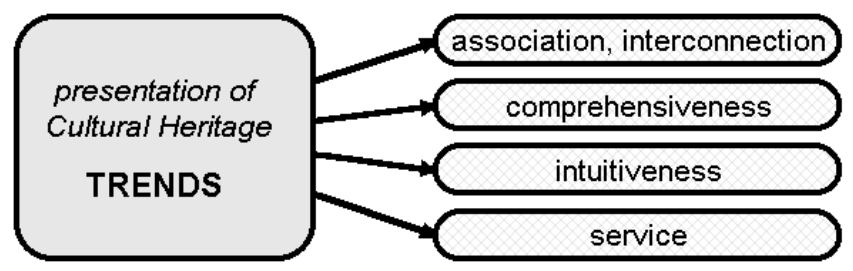

Fig. 2: Presentation of the Cultural Heritage - trends 
The results of the analysis of how sites abroad are presented provided some interesting information about current trends, see Fig. 2. These trends all aim at the same goal, to facilitate understanding of the significance of the cultural heritage to visitors. Complex 3D models of real sites were not included in this selection. Interactivity was mainly used in connection with traditional forms of data (text, photos).

\subsection{Proposal for a conception of a 3D IS of historical site}

The proposal of a conception for IS is based on three areas of utilisation. These areas also determine the IS subsystems.

A complex information system including 3D data should comprise subsystems dealing with site management, site research, and site presentation.

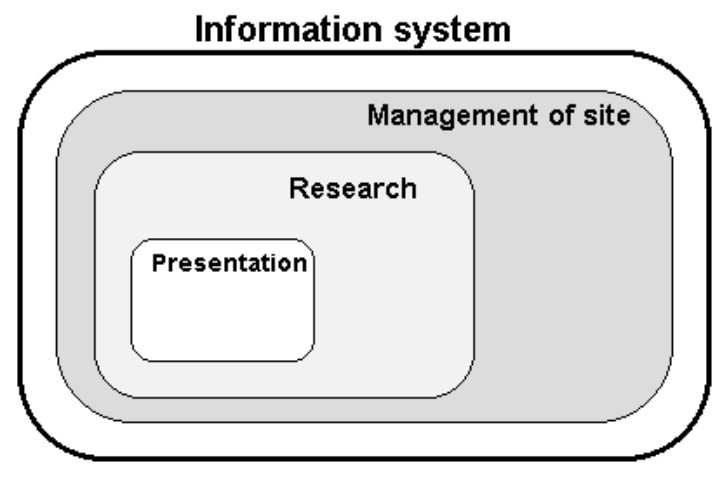

Fig. 3: Subsystems of IS of historical site

The subsystems use the same data set for a variety of purposes. Fig. 3 shows the volume of data for each subsystem.

The results of the analytical part of the study formed a basis for defining the principal features of an information system of a historical site and its subsystems:

Subsystem - site management (s-SM)

- intended for site management, to support the decision-making process

- for use by site administrators

- the subsystem enables: updating and editing of data; making outputs with the use of various types of data $(2 D$, 3D); simple spatial analysis, etc.

Subsystem - site research $(\mathrm{s}-\mathrm{SR})$

- intended for studying of site and its resources

- for use by historians, conservationists, restorers and students

- the subsystem enables: work with other associated systems; basic analysis of examined data, e.g., modelling; feedback $\rightarrow$ discussions, publications, etc.

Subsystem - site presentation (s-SP)

- intended for presentation of the site

- for use by potential visitors to the site

- the subsystem enables: work with virtual reality and interaction; work with other associated systems; complete service for visitors, etc.

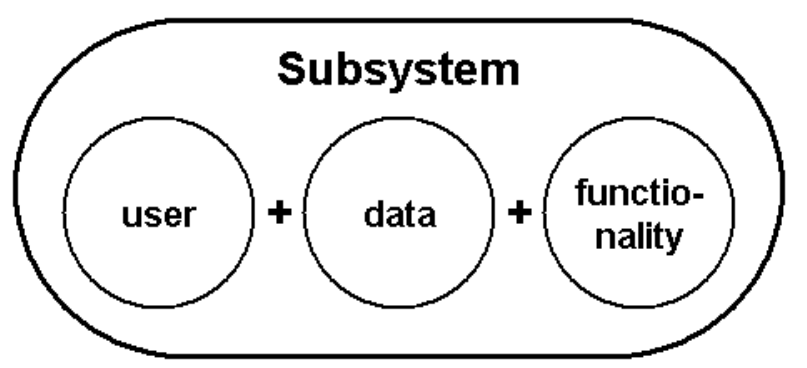

Fig. 4: Basic factors influencing a specification of the subsystems

Fig. 4 shows factors which were considered in a detailed specification of the subsystems.

User - future users determine the content and form of IS. Users of IS of a historical site may have various areas of interest, see above.

Data - the subsystems all have the same set of original data. The requirements for the subsystems differ, and therefore the volume and form of the accessible data also varies, see Fig. 3.

Functionality - the demands on functionality of the whole IS are given by the previous two levels: user and data. Although the subsystems have the same set of basic functions, each subsystem also needs a specialised function.

\subsubsection{Basic conditions for realisation}

Apart from the content of IS, the fundamental conditions for successful realisation and use of IS were also defined. These are: utilisation of network technologies low installation cost inexpensive hardware and software simple handling lucidity update of data.

A detailed proposal for the technical solution goes beyond the scope this stage of the project. The concept of a distributed system is a possible approach. The data can be stored not in one central powerful server, but on several servers. This concept could be demonstrated in conditions of public cultural heritage care (in CZ) on a typical relation administration of the site $\Leftrightarrow$ founder or administration of the site $\Leftrightarrow$ network (or fund) administrator. Fig. 5 illustrates this concept.

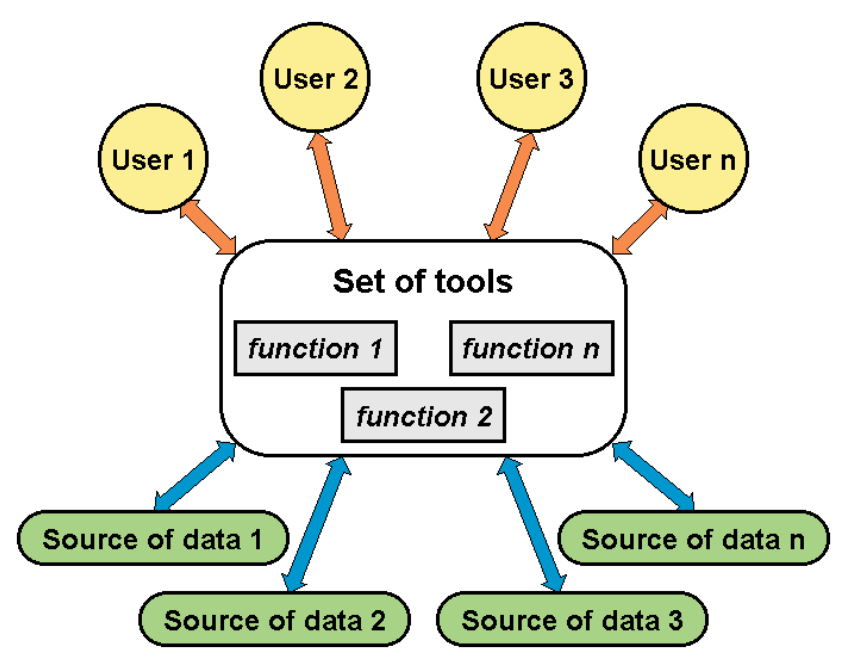

Fig. 5: Distributed system 


\subsection{The "Live Theatre" project}

An IS project was designed at the end of this stage. The main goal was to document and elaborate the results of the previous phases in detail. The "Live Theatre" project arose as follow-on to previous work by students and teachers of the Department of Mapping and Cartography on the baroque theatre at Český Krumlov castle.

Both geometric and non-geometric data was available. Subsystems for management, research and presentation of the site were elaborated in greater detail in close connection with the general outcomes of previous phases. Schemes of selected prototype data for each subsystem were created. The parameters of the technical solution were specified at the end of this phase.

The present state of the castle theatre in Český Krumlov is the result of reconstruction of the castle's area in 1765-66. The theatre represents a baroque stage in its mature form. The original theatre fund is preserved in both actual objects such as the building, auditorium, orchestra pit, stage, stage technology, machinery, decorations, costumes, props, lighting technology, fire extinguishers, etc., as well as in rich archival documentation such as librettos, scripts, texts, partituras, sheet music, inventories, accounts, iconographic material, and other information on theatre life in the 17th to 19th century. The Krumlov theatre was closed to the public from 1966 to 1997 , and after a large part of the restoration had been completed, trial tours of the theatre began in September 1997.

\subsubsection{Initial sources}

Both geometric and non-geometric data were available.

Geometric data - this comprises a 3D model of the interior and exterior of the theatre. This model was created in stages. Photogrammetric and surveying methods of documentation were used, according to the type of area to be documented. The creation of a 3D model is described in greater detail in
[4]. CAD system MicroStation was used as a tool for creating the model. This 3D model is photo-realistic, and can be used for visualization and animation purposes. Fig. 6 shows a visualization of the upper stage part of the theatre.

Non-geometric data - the original wide-ranging theatre funds are gradually being restored, recorded and catalogued. The project to digitize the most important funds was completed in 2002. Now there is a digital form of the "Basic Inventory of Funds" (BIF) which contains the following items (funds): costumes and props, decorations, technical and lighting equipment. BIF is based on card and photo documentation of each element.

The fund of technical equipment and part of the fund of decorations were 3D metrically documented, see above. In these funds, 3D information is clearly relevant.

Additional sources of non-geometric data are: photo documentation, panoramic videos (see [5]), videos (rehearsals), collections of sounds (scenic effects), historical plan documentation, etc.

For the purposes of the IS proposal, non-geometric data for two funds was chosen - the technical equipment fund and the decorations fund.

The decorations fund consists of sets of 13 basic stage scenes.

The technical equipment fund includes complete original theatre machinery with sliding frames, winches, levers, pulleys, and a movable lighting rack. The floor of the stage is also original, including sliding and removable planks and trap doors.

\subsubsection{Proposal for IS}

The IS project for the theatre has the working name "Live Theatre". The objective of the project is to create a living system, which can be used to gain an insight into the baroque theatre culture and more widely to recognise general interrelations in life in the baroque epoch.

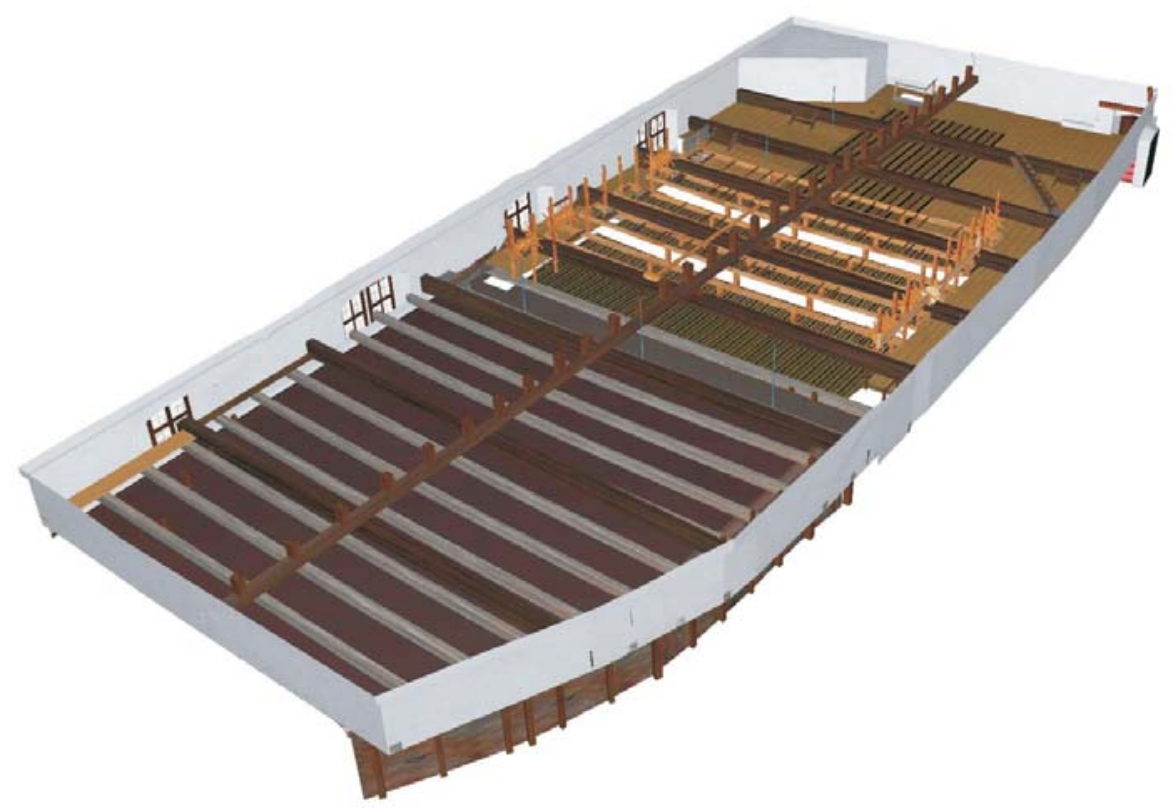

Fig. 6: Visualization - upper stage, roping gear 


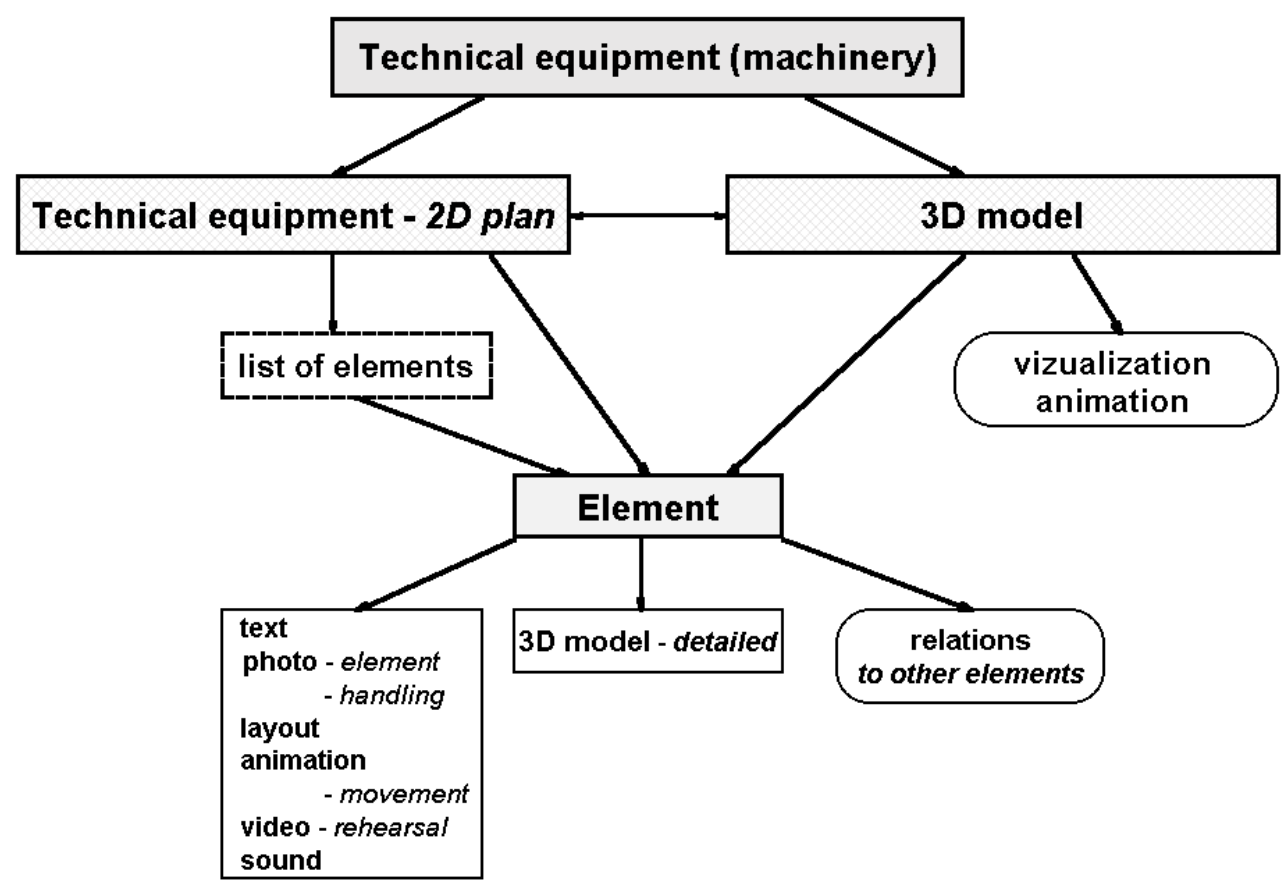

Fig. 7: Scheme of data, subsystem - site research, technical equipment element

The project is being implemented in close co-operation with the administration of Ceský Krumlov castle and the Baroque Theatre Foundation.

The schemes of data for the two fundamental funds were designed for each subsystem. The following topics were further elaborated: user, functionality, data, form, and future development of IS.

A basic segment of the proposed IS structure is an element. This element is connected with textual, graphical and other information. The existence of an element is given by the existence of a BIF card.

Various ways to obtain information on an element are designed for users. Geometric data forms the basis, see Fig. 7 and Appendix A. The user can choose a "traditional 2D approach", i.e., selecting a fund + an element on a 2D plan or from a list of elements. Another way is the "3D approach", i.e., selecting a fund + an element inside a 3D model. The direct route - query to database - is also available.

All the above-mentioned approaches can be combined. For example, the user can switch between 2D and 3D data.

- For geometric 3D data, functions enabling various operations with the $3 \mathrm{D}$ model are included in the IS proposal. The functions allow interactive work with the model (movement in virtual space, identification of elements); work with a detailed model of an element (browse); visualization (making views); viewing animations (walk through, movement of elements, exchange of scenes, interrelations of elements). The baroque theatre is a stable system with a limited number of elements. The $3 \mathrm{D}$ data will not need to be edited frequently.

- Non-geometric data referred to an element consists of textual information (mainly BIF), photo documentation (BIF and others), video (rehearsal, panoramic views, etc.), sounds, drawings (technical drawings of elements and their relations, etc.).

Main features of the subsystems - were defined in chapter 2.3. Proposed subsystems have following attributes:

$\mathrm{s}-\mathrm{SM}$ - collects a complete set of data from selected funds,

$\mathrm{s}-\mathrm{SR}$ - attention is given to elements, and especially to their interrelations and dependencies,

s-SP - the main feature is interactive work with a 3D model, which enables the user to find his own way to recognize the site.

\subsubsection{Technical solution}

The technical solution will be based on the results mentioned in chapter 2.3.1. The requirements for the technical solution can be placed into three groups - operating, technological and data. The operating group concerns requirements for low costs (hardware and software), and easy and intuitive operation. The technological group concerns utilisation of network technology, open source software and convenient database organisation. The data group concerns utilisation of a standard data format, metadata, security of data, and multilingualism.

\subsection{Functional prototype of IS}

The present stage of the project involves producing a functional prototype (with sample data, see 2.4.1). During this stage we are working step-by-step on basic technological topics:

\footnotetext{
- 3D data: formats, conversion, interactivity,

- interconnection of geometric and non-geometric data,

- technical solution of IS: network, database,

- functional prototype: realisation, testing.
} 


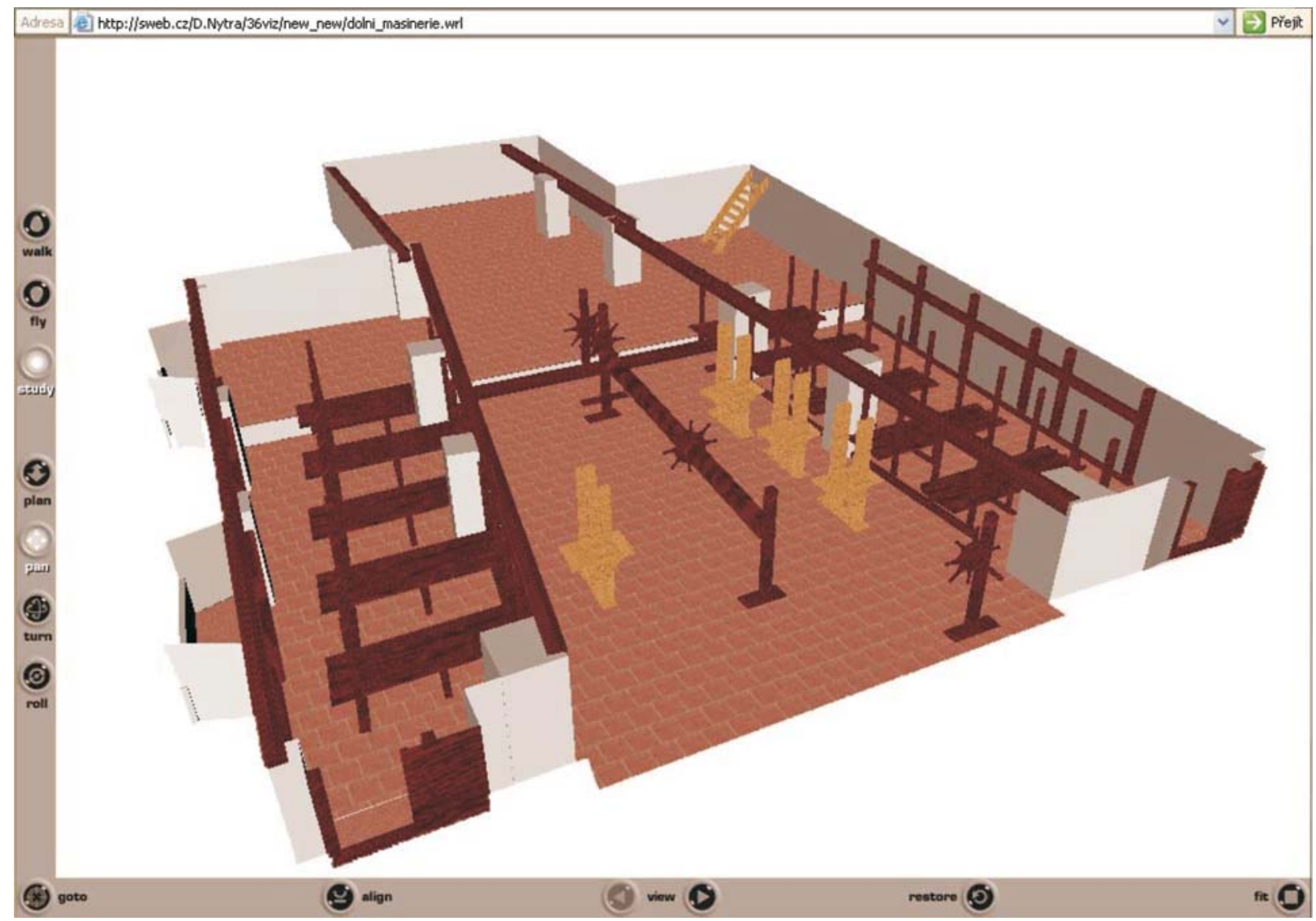

Fig. 8: VRML model - lower stage, machinery

3D data: we are now concerned with 3D data, its formats, format conversions and interactive work with this type of data. The existing $3 \mathrm{D}$ model is in DGN format. This format is not very convenient for the purposes of the proposed IS. Existing formats of 3D data (VRML, VET, and X3D) were analysed and VRML format was selected. VRML is a standard format for 3D data on Internet, and it has been used successfully, see $[2,6]$. It is sometimes very problematic to convert the formats. The $3 \mathrm{D}$ model of the theatre is complex, comprising both the interior and the exterior of the building. Two approaches to conversion are being tested: standard export to $\mathrm{dxf} \rightarrow$ optimization of $\mathrm{dxf}$ (specialised $\mathrm{SW}) \rightarrow$ export to VRML; and export interactively controlled by the user (directly DGN - VRML or DGN - dxf - VRML). A special conversion program needs to be created for the second approach. The existing conversion results are documented in Fig. 8.

The next step is to create a set of tools for interactive work with this type of model. This will enable, e.g., measurements of distances, work with layers, selection of elements, etc.

Forthcoming steps will include searching for a suitable technological solution.

Interconnection of geometric and non-geometric data: elements of the VRML model will have a direct link with additional data (see above).

Technical solution of IS: future users will work with IS via the Internet. An appropriate layout of all types of data will play a major role in the usability of IS. Storing 3D data directly in a database is a promising option that is now being studied, see e.g. [7].

Functional prototype - production, testing: at the end of this stage, a functional prototype of IS will be built on the basis of technologies verified in the previous steps, taking into account its functionality. This prototype will be tested by a sample of future users.

\section{Outcomes of the project}

A functional prototype and information acquired by testing it will form the basis for the final proposal for a complex information system of a historical site. The final proposal and an appropriate technology will be the outcomes of the project. A complex 3D information system will than be created.

\section{Conclusions}

This project focuses on the cultural heritage area. The main aim is to create a 3D IS of a particular historical site. The results of the individual stages of the project can be summarised as follows:

- The analyses were made on a selected sample of historical objects. The first analysis dealt with the current state in the management of the site, with special reference to sources of data and their usage, and on the potential use of information technologies. An analysis was made of the presentation of cultural heritage sites on the Internet, using a 3D model and virtual reality. 
- The proposal for a conception of 3D IS was based on information acquired in the analyses. Areas for using 3D data (and IS) were defined and IS subsystems were drafted. These deal with site management, site research and site presentation. The subsystems all have the same set of original data. The basic technical requirement is network technology.

- Conclusions reached during the previous stages were used to create a conception of IS for a specific site, the baroque theatre at Český Krumlov castle. An appropriate data set was selected and a scheme of data was created for each subsystem. We also paid attention to the functionality of the subsystems, taking into account work with a 3D model and 3D information.

- Producing of a functional prototype of IS is the current stage of the project. The focus is now on converting the 3D model format from DGN to VRML. Finally, the prototype will be tested. The results, together with the tested technology, will form the basis for creating the final proposal of 3D IS of a historical site.

The project offers an overall, complex view of the topic. That is being studied comprehensively for the first time in CZ. We have tried to reflect current trends in $3 \mathrm{D}$ information technologies and their application in the area of cultural heritage, and to adapt them to the conditions of the Czech Republic.

\section{Acknowledgments}

This project is part of the research activity of the Department of Mapping and Cartography (supported by MSM:210000007). Presentation of the results of the project is supported by the Baroque Theatre Foundation in Český Krumlov.

\section{References}

[1] Hodač, J.: „Návrh koncepce prostorového informačního systému památkového objektu." Stavebni obzor, Vol. 13, (2004), No. 2, p. 45-50.

[2] Zlatanova, S., Rahman, A. A., Pilouk, M.: "Trends in 3D GIS Development.” Journal of Geospatial Engineering, Vol. 4, (2002), No. 2, p. 1-10.

[3] Santana, M.: "A Witness to Enhanced Realities in Virtual Heritage: Potentials and Limitation.” Berkeley, USA, 2001, Virtual Systems and MultiMedia conference. WWW: www.virtualheritage.net/news/article.html

[4] Hodač, J.: "Documentation of the Baroque Theatre at Český Krumlov Castle.” In: The International Archives of Photogrammetry, Remote Sensing and Spatial Information Sciences. Potsdam, ISPRS, Vol. XXXIV-5/C7, p. 121-125.

[5] OIS CK.: „Oficiální informační systém regionu Český Krumlov“. WWW: www.ckrumlov.cz.

[6] Schürle, T., Fritsch, D.: "CAFM Data Structures: A Review and Examples." In: IAPRS, Vol. 33, Amsterdam, IAPRS, 2000, p. 124-128.

[7] Stoter, J., Zlatanova, S.: "Visualisation and Editing of 3D Objects Organised in a DBMS." In: EuroSDR Com. V. Workshop, Enschede, EuroSDR, 2003, p. 32-48.

Ing. Jidřich Hodač, Ph.D.

phone: +420224354650

e-mail: hodac@fsv.cvut.cz

Department of Mapping and Cartography

Czech Technical University in Prague

Faculty of Civil Engineering

Thákurova 7

16629 Prague, Czech Republic 


\section{Appendix A}

Scheme of data, subsystem - site research, technical equipment element

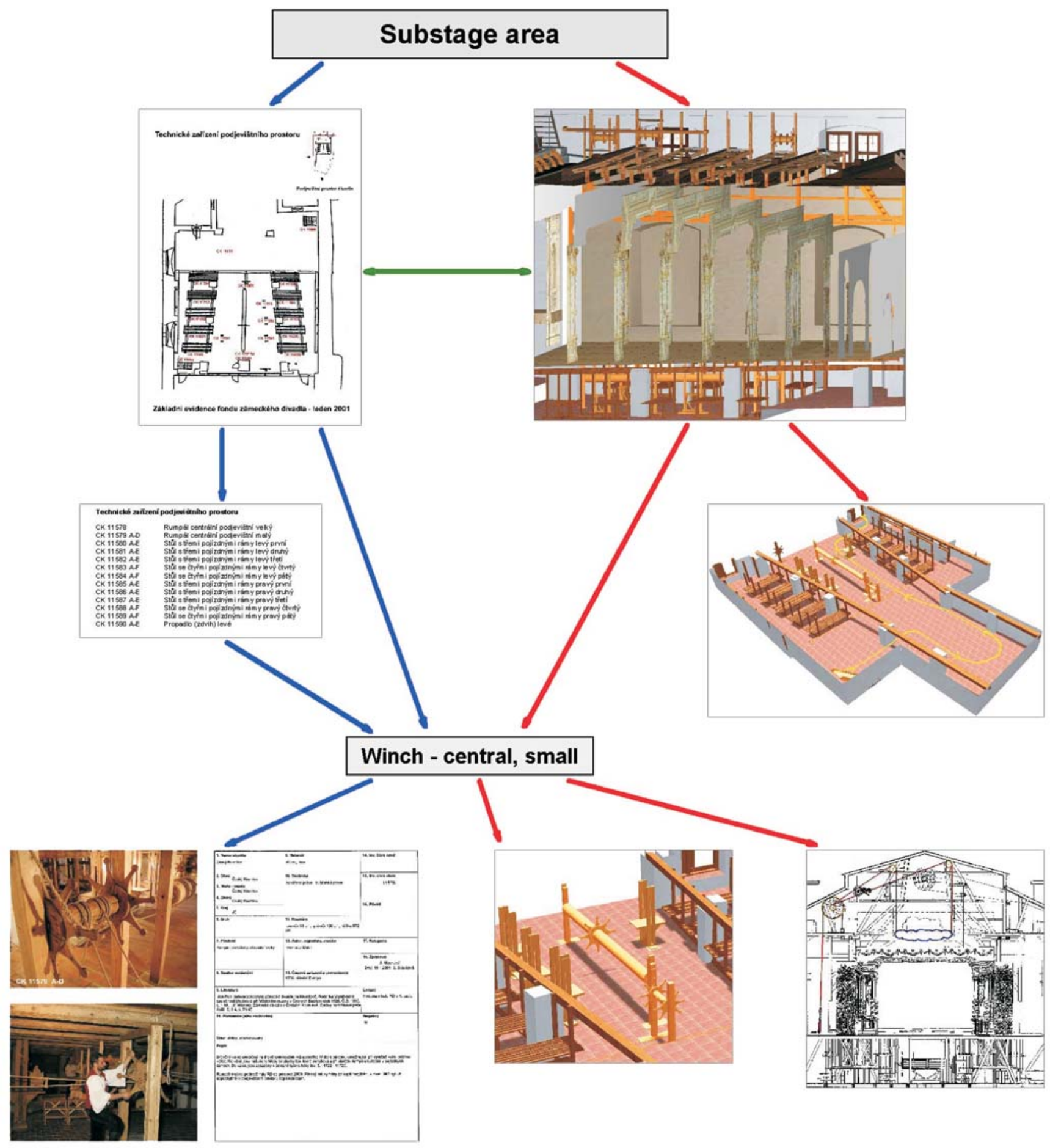

